\title{
Exploring Preservice Elementary Teachers' Mathematical Knowledge for Teaching
}

\author{
Josephine C. Pelingon \\ Mathematics Unit, College of Education Leyte Normal University, Tacloban City
}

\begin{abstract}
Mathematical knowledge for teaching is a construct currently explored in research and is found to be one of the best predictors of student achievement in mathematics. This study assessed the readiness and characterized student teachers' mathematical knowledge for teaching elementary mathematics. Data were collected through a teachermade instrument measuring mathematical knowledge for teaching which consists of the domains common content knowledge, specialized content knowledge, knowledge of content and students and knowledge of content and teaching. Results of the study show that these pre-service teachers have very low performance in the test, an indication that they were not adequately equipped with the subject matter and pedagogical content knowledge needed for teaching elementary mathematics. In the light of the findings of the study, future elementary mathematics teachers should take courses that will help them acquire the subject matter and pedagogical content knowledge needed for teaching the subject during their teacher preparation program.
\end{abstract}

Keywords: Mathematical knowledge for teaching, subject matter knowledge, pedagogical content knowledge, pre-service teachers, elementary mathematics

DOI: $10.7176 / \mathrm{JEP} / 10-12-08$

Publication date: April $30^{\text {th }} 2019$

\section{Introduction}

The current state of mathematics education in the country both in the basic education and tertiary levels is very problematic as shown in the results of international and national examinations such as the Trends in International Mathematics and Science Study (TIMSS), Teacher Education and Development Study: Learning to Teach Mathematics (TEDS-M, and the Philippine National Achievement Test (NAT). TIMMS (2003) reveal that grade four pupils and second-year high school students got overall achievement rates of 358 and 378 in Mathematics, respectively. These overall achievement rates fall below the international benchmark of 400 set by TIMMS. Similarly, in the TIMMS - Advanced (2008) which was participated in by students taking special science curriculum, the Philippines ranked last, with an average scale score of 355 out of ten participating countries. The overall average percent correct in the advanced mathematics content areas and cognitive domains obtained by Filipino students is 24 , also the lowest among the ten countries who participated in the assessment. In general, out of the 4901 students who took the test, only $1 \%$ of the students reached the advanced benchmark, $4 \%$ reached the high benchmark and $13 \%$ to the intermediate benchmark (Ogena, et al. 2010). It worth mentioning that the performance of students coming from the Philippine Science High School system in terms of overall average percent correct in the content areas in Algebra, Calculus and Geometry and knowing, applying and reasoning domains is comparable to the performance of students from the three top performing countries, the Russian Federation, the Netherlands and Lebanon. Likewise, initial results from Teacher Education and Development Study: Learning to Teach Mathematics (TEDS-M, 2008), show that the overall mean performance of Filipino preservice primary teachers on mathematical content knowledge and pedagogical content knowledge were 440 and 457 , respectively. These results are also way below the highest scoring countries, Taiwan and Singapore, which posted an overall mean achievement of 623 and 593, respectively. The National Achievement Test (NAT) results in mathematics for SY 2011-2012 show a mean percentage score (MPS) of $66.79 \%$ and $46.37 \%$ for grade six and fourth-year high school examinees respectively. These results are behind the target of $75 \%$ MPS set in the 2016 Philippine Development Plan especially for the fourth-year examinees.

Research findings show that the inadequacy of teachers' knowledge of mathematics and how they teach it is one of the major reasons why students are not learning the mathematics they are supposed to learn in school (Mewborn, 2003; Ball, 2000; Ball, Hill \& Bass, 2005; Hill, Rowan \& Ball, 2004; Mapolelo \& Akinsola, 2015 ). A report from the Teacher Professional Development: A Primer for Parents and Community Members (2008), states that quality teachers are the most significant determinant of student achievement. Ma (1999), in her book Knowing and Teaching Elementary Mathematics, stated that teachers of mathematics, especially those who teach at the elementary level, generally do not possess the knowledge necessary to help empower future generations of adults mathematically. She calls this as the "vicious cycle" formed by low-quality mathematics education and lowquality teacher knowledge of school mathematics" (p. 149). Moreover, in a Discussion Paper Series No. 2008-16 entitled "Measures for Assessing Basic Education in the Philippines," Maligalig and Albert stressed that the low achievement rates for both elementary and secondary schools in the Philippines are indicative of the low quality of elementary and secondary education. They further argued that a contributing factor to the low quality is the lack 
of competent teachers who are the primary resource for elementary and secondary students instead of books and other learning materials.

What types of mathematical knowledge should teachers have to be able to teach the subject proficiently and efficiently is a fundamental question that is currently being explored by researchers and mathematics educators worldwide. Traditionally, it is assumed that to teach successfully, teachers need to have a firm knowledge base of the mathematics content they teach be it in the elementary, secondary or tertiary level. Such content knowledge is gained through the formal study of the different content subjects pre-service teachers take to complete the academic requirements prescribed in the teacher education curriculum. This knowledge can be acquired through reading textbooks, taking notes, observing teachers' demonstrations, listening to teachers' explanations, and completing practice problems (Walters, 2009). However, teachers do not only need subject matter knowledge to be able to teach the subject effectively. They also need another kind of knowledge that will enable them to provide students with explanations as to why a procedure works, to analyze and correct student errors and misconceptions and to use appropriate examples for representing mathematical concepts, etc. Such knowledge is what Shulman (1986) calls as pedagogical content knowledge. Ma (1999) describes this knowledge as the flexibility in grasping multiple perspectives and understanding the connection of ideas. She further stresses that it is essential that teachers should have a profound understanding of fundamental mathematics (PUFM) to be able to teach it. Hill et al., (2005) call this knowledge, mathematical knowledge for teaching mathematics (MKT).

Recent developments in the field of teaching and learning mathematics saw the emergence and conceptualization of a framework for teaching mathematics called mathematical knowledge for teaching (MKT). Thames, et al. (2004) define MKT as the "mathematical knowledge needed to perform the recurrent tasks of teaching mathematics to students." Currently the MKT framework is categorized into two major categories, namely; subject matter content knowledge and pedagogical content knowledge. Under the subject matter knowledge domain are common content knowledge (CCK) - the mathematical knowledge and skill used in settings other than teaching and specialized content knowledge (SCK) - the knowledge and expertise unique to teaching. Pedagogical content knowledge (PCK) includes knowledge of content and students (KCS) which is the knowledge that combines knowing about students and knowing about mathematics and knowledge of content and teaching (KCT) which combines knowing about teaching and knowing about mathematics (Ball et al., 2007).

With the emergence of a new conception of the content knowledge that teachers need to know to be able to teach mathematics comes the problem on how this knowledge will be measured. Previous researches on teachers' knowledge show that teachers' effectiveness was evaluated through proxy variables such as educational qualification, certification status, number of mathematics and methods courses taken in college, years of teaching experience and number of trainings attended, self-report of what they do in their classrooms, principal and students' evaluations, classroom observation reports, analyses of videotaped lesson and giving examination on content to both teacher and student, etc. However, according to Ball et al. (2004), most of these types of assessment do not capture the mathematical knowledge and reasoning needed to perform the task of teaching. In the Philippines, researchers still use proxy variables in assessing mathematical knowledge for teaching. For instance, Sogillo et al. (2016) evaluated the quality of mathematics teachers in a public school and a private school, measured teacher quality by asking the teachers themselves the frequency of practicing in their classes the teaching methods/approaches outlined in a 50-item questionnaire. Agsaluad, (2017) also measured teacher quality by asking students to rate their teachers using the NBC No. 461 teaching effectiveness instrument. Both studies concluded that their respondents are highly effective teachers. However, conclusions derived from self-report and students' perceptions seem not to be valid because the instruments used did not capture the work of teaching as describe by Ball and colleagues.

After a thorough review of literature, Hill, et al. (2004) felt the need to map out differing views and conceptions held by teaching experts and researchers about mathematical knowledge for teaching and how it should be measured especially on large scale population. Guided by the questions, "What mathematical knowledge is needed to help students learn mathematics?" and "Can we construct reliable measures that accurately represent teachers' ability in these areas?", they developed a survey consisting of multiple-choice items intended to measure mathematical knowledge and skills needed for teaching elementary mathematics. Exploratory factor analyses were conducted in order to find underlying dimensions represented by the items in the survey and item response theory (IRT) one-parameter model was employed to establish the reliabilities of the item. The authors reported that MKT is partly domain-specific, rather than just related to overall intelligence, mathematical or teaching ability. Content areas covered by the measure are numbers and operations, geometry, patterns and functions, and algebra. In 2008, sample items of the MKT measure were released.

Since its release, studies conducted using the MKT instrument, generally fall into adaptation and validation done in other countries for both in-service and pre-service teachers or as a material for professional development of teachers.

Using a mixed method design of data collection, Jóhannsdóttir (2013), investigated the level of elementary mathematical content knowledge for teaching of 38 pre-service teachers at the School of Education, University of 
Iceland. Adapted items from the MKT released item 2008 were used to collect data on the MKT levels of the participants. Interviews were also conducted to 10 respondents in order to elicit how they think during a problem solving activity and how they explain their solutions. Findings of the study indicated that prospective teachers' common content knowledge was procedural. They can solve mathematical problems, however, they could not explain underlying reasons for their solutions. Item difficulty analysis using an item response theory model was used to identify which items were found easy or difficult by the participants. Common content knowledge items found most difficult by the prospective teachers are: identifying surjective function, statement about multiplication, properties of positive and negative numbers, multiplying fractions, algebra problem, needing a system of equations to solve problems. In terms of specialized content knowledge, difficult topics are: alternative method to divide fractions, explanation for equivalent fractions, division rules, visual model for multiplication, alternative subtraction method. In general, and in both knowledge domains, the source of difficulty among the pre-service teachers was on fractions.

Nolan et al., (2015) studied the development of MKT using a pre - and post-test method with two groups of pre-service teachers at two Irish universities. Two measurements were taken from the sample- the MKT level and MKT awareness. The MKT level was measured using a subset of the LMT released items on integers, fractions and basic geometry while level of MKT awareness was measured by asking the pre-service teachers to list down different teaching situations where a teacher uses his or her knowledge of mathematics. The intervention was the delivery of a specially designed mathematics pedagogy course intended to improve students' MKT. After the intervention, the MKT level of the participant significantly increased. Fifty-five items that were incorrectly answered in the pre-test were already answered correctly in the post-test was also reported by the researchers.

A large scale study by Jakobsen, et al., (2018) evaluated whether the initial primary teacher education (IPTE) program of Malawi can develop pre-service teachers' knowledge to teach mathematics in their primary schools. Participants were 1,700 students enrolled in the primary education program from 8 public teacher colleges in the country. A pre- and post-test design was employed to gauge the improvement of pre-service teachers' MKT. Two forms of adapted MKT measure were administered as pre-test and post-test. A paired sample t-test show that the post-test scores were significantly higher than that of the post-test, indicating a positive impact of the IPTE program.

To establish whether a relationship exists between the mathematics courses of the Diploma in Basic Education(DBE) and mathematical knowledge for teaching, Asante and Mereku (2012) analyzed the performance of 100 randomly selected pre-service teachers enrolled in the Colleges of Education in Ghana using two data sets, mathematical knowledge for teaching (MKT) scores and DBE examination results. The MKT scores were measured through an adapted instrument from the MKT instrument developed by Ball, et al (2005) while DBE examination results were obtained from the previous records of respondents' first year mathematics content examination. The overall performance of the pre-service teachers in the MKT test was low with only $8 \%$ of them obtained marks from $60 \%-73 \%$ of the items while $75 \%$ of them got marks from $32 \%-51 \%$. In terms of content domains, the pre-service teachers performed better in number patterns than in fractions and number operation. Contrary to the researchers' expectation, the pre-service teachers scored lowest on number operations. Result of the DBE examination indicated that only $10 \%$ of the respondents got scores of $77 \%$ and $50 \%$ of them did not score beyond $63 \%$. A correlation coefficient between the DBE examination result and MKT score was computed, $(\rho=.388$, at $\alpha=.01$ ) indicating a positive moderate correlation.

Considering the impact of mathematical content knowledge and pedagogical content knowledge on how mathematics teachers design their instructional environment, it is of paramount importance to explore the extent to which such knowledge is exhibited by pre-service teachers before exiting from their teacher education preparation program. Moreover, taking into consideration the current state of mathematics education in the country, it is imperative that this situation be addressed and one of the most logical ways is to improve the quality of teachers' knowledge for teaching mathematics. Perhaps an appropriate starting point for improvement is an assessment of the mathematical knowledge in both content and pedagogy that pre-service teachers gain from their teacher preparation program.

Although this study also explored the mathematical knowledge for teaching of pre-service teachers, it is different from the studies previously reviewed because actual items from the MKT instrument released in 2008 did not from part of the instrument used to measure pre-service teachers' knowledge for teaching. Instead a researcher-constructed following Hill, et al. (2004) conceptualizations of the four domains of MKT was used in the study.

\subsection{Methodology}

\subsection{Respondents of the Study}

Data for this study are from the scores of 176 mostly female pre-service teachers (PST's) enrolled in state colleges and universities and three private higher education institutions (HEI) in Region 8 offering teacher education specifically the Bachelor of Elementary Education (BEED) program. All PST's present on the day of the survey 
were asked to answer the test items. These answer sheets and a table of random numbers were used to draw the sample of the study. For example, in an HEI where there were 340 PST's who took the test, answer sheets were numbered from 001 up to 340 . Using random start and taking 85 students ( $25 \%$ as the sample size for each HEI), a random start equal to 38655 gave the answer sheets numbered 70, 38, 45, 55, and 83 first five samples. For all HE's $25 \%$ of the PST's enrolled during the term form part of the respondents of the study. At the time the test was administered these PST's were about to finish the third shift of their practice teaching program.

\subsection{Research Instrument}

The instrument used to gather the data in this study is patterned after the 2008 Mathematical Knowledge for Teaching (MKT) released items. Hill, et al. (2004) describe the items in the instrument as content tasks that teachers encounter in teaching such as interpreting and evaluating student answers to problems, choosing appropriate materials for teaching specific concepts and skills, explaining concepts and procedures, identifying students' misconceptions, probing into students' thinking why a procedure works, etc. Test items were developed only for the content areas on numbers and operations and geometry because these are the mathematical content taught at Grades 5 and 6 in the elementary school curriculum in the Philippines.

Before gathering the data for this study, the content validity and reliability of the instrument were established. Three faculty experts were asked to evaluate whether the items measured mathematical knowledge for teaching by benchmarking on the examples described by Ball et al. (2004). Comments and suggestions from the faculty experts were incorporated in the revised form of the instrument. Pilot testing was conducted to a sample of fifty student teachers enrolled at Leyte Normal University. This group of students was excluded in the actual conduct of the study. The revised instrument has a Cronbach alpha equal to 0.83 , which indicates an acceptable internal consistency of its items (Tavakol \& Dennick, 2011). The final form of the test contains 35 items with the following breakdown: 8 questions on common content knowledge (CCK), 8 items on specific content knowledge (SCK), nine items on knowledge of content and students (KCS) and 10 items on knowledge of content and teaching KCT).

\subsection{Design and Procedure}

Since the main goal of this study was to examine teacher candidates' knowledge and understanding of mathematics needed for teaching and to establish relationships on some variables, a combination of survey and correlational method was used. A permit to conduct the study was sought from the presidents of the different state colleges and universities (SUC's) and private higher institutions offering teacher education program in Region 8 . The deans of these institutions were furnished with the approved letter of permission to facilitate and expedite data collection. The instrument was administered by the researcher herself. Adequate time to answer the items was afforded to the respondents of the study.

\subsection{Data Processing}

The respondents' overall performance on the instrument was analyzed quantitatively. Descriptive statistics means, standard deviations and percentile rank were used to describe the respondents' scores. A paired sample t-test was computed to find whether differences exist in the PSTs' scores in the MKT items. Item difficulty indices were used to determine which specific areas in the MKT items were found difficult by the pre-service teachers. Item difficulty is defined as the proportion of examinees who answered an item correctly. A common rule of thumb with the following values of difficulty indices were used categorized the difficulty level of each item.

Table 1. Classification of Difficulty Index

\begin{tabular}{cl}
\hline Difficulty index & Level of difficulty \\
\hline $0-.20$ & Very difficult \\
$.21-.40$ & Difficult \\
$.41-.60$ & Average \\
$.61-.80$ & Easy \\
$.81-100$ & Very easy \\
\hline
\end{tabular}

\subsection{Results and Discussions}

\section{Pre-service Teachers' Performance in the Mathematical Knowledge for Teaching Test}

Figure 1 shows the stem and leaf plot of the PST's scores in the MKT measure. Out of 35 items of the highest score is 21 and the lowest is 5 with a mean of 11.95 and a standard deviation of 3.28 . The mean score of 11.95 shows a very big gap from the perfect score, and the bulk of the scores ranged from 8 to 15 which was obtained by 138 of around $80 \%$ of the student teachers. However, only 16 or $9 \%$ of them were able to answer correctly $50 \%$ or more of the items in the test. Ideally an examinee with an average ability is expected to answer 50 percent of the items in a test. Clearly, these results indicate that the PST's performed very low on the MKT measure. This is consistent with Jóhannsdóttir (2013); Asante and Mereku (2012) findings that majority of preservice teachers have an inadequate understanding of the mathematics content knowledge necessary for teaching in the elementary 
grades. This low performance level could be explained by the lack congruence between the lessons taught in the content courses with the lessons they will teach in the future. Although they took 18 units of content courses and 54 units of professional education courses, only one course has a content parallel to the items in the MKT instrument. Not one among these courses addresses developing specialized content knowledge, knowledge of content and students and knowledge of content and teaching. Only one course of the 18 units of content courses deals with the content knowledge these pre-service teachers will teach in the future. This result further suggests that the kind of knowledge necessary for teaching mathematics as described by Shulman (1986); Ma (1999); Ball et al., (2005) is not addressed in the mathematics courses offered in the teacher education curriculum.

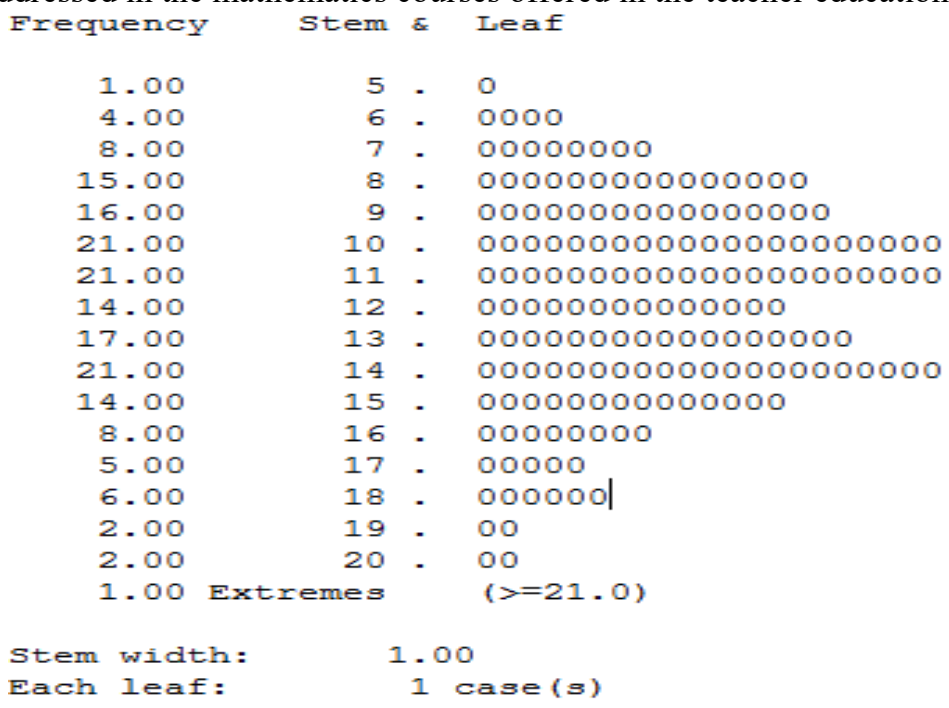

Figure 1. Stem and leaf plot of the PST's MKT scores

\section{Mathematical Knowledge Items Found Difficult by Respondents}

Difficulty index is a behavioral measure defined as the proportion of examinees answering an item correctly. It is both a characteristic of the item and the examinee and is relevant to for assessing whether a student has learned the concept being tested. For the purpose of this study, items in the MKT test were classified using the common rule of thumb presented under the data processing portion of this article. Tables 2 presents the number or percentage of respondents who correctly answered the items in the test, difficulty levels and item domains. Twenty-four or around $70 \%$ of the items were found difficult and very difficult by the pre-service teachers. Ten of these items are under the SMK domain (common content knowledge - 4; specialized content knowledge - 6) and 14 items were on the PCK domain (knowledge of content and students -6 ; knowledge of content and teaching -8 ). This indicates that the examinees encountered more difficulty on PCK items than SMK items. This difficulty may be due to students not learning the content and non-exposure to activities that may develop both SMK and PCK in the different content and pedagogy courses offered in their teacher education curriculum. The most difficult was item 32 which is asks for an appropriate example to introduce the concept of primes and composites. Item 6 which is a knowledge of content and teaching was the only item found very easy by the respondents. This item asks about the most appropriate tool to use to introduce the idea of grouping by tens to students. Basically, this concept is introduced as early as grade one. The most difficult item was on choosing appropriate examples for dividing fractions. This was correctly answered by only 11 or $6 \%$ percent of the study sample. This difficulty can be explained by the PST's lack of mastery of the concepts and skills about fractions. In fact, three of the most difficult items were on fractions. The PST's may be able to perform operations using varied strategies but they cannot explain why a procedure work because their conceptual understanding of fractions is fragmented and disconnected, (Nillas, (2003); Leung, \& Carbone, (2013); Son, \& Lee, (2016); Bentley, \& Bossé, (2018). It follows that without a strong conceptual understanding of fractions one will not be able to identify an appropriate example for dividing fractions. 
Table 2. Percent of correct responses, item domain and difficulty level of the MKT items

\begin{tabular}{|c|c|c|c|c|}
\hline Item number & Number of Correct Responses & Difficulty Index (\%) & Item Domain & Difficulty Level \\
\hline 6 & 144 & 82 & KCT & Very easy \\
\hline 7 & 116 & 66 & $\mathrm{KCS}$ & Easy \\
\hline 3 & 101 & 57 & CCK & Average \\
\hline 15 & 85 & 48 & SCK & Average \\
\hline 10 & 84 & 48 & CCK & Average \\
\hline 9 & 79 & 45 & $\mathrm{CCK}$ & Average \\
\hline 13 & 77 & 44 & SCK & Average \\
\hline 19 & 77 & 44 & $\mathrm{KCS}$ & Average \\
\hline 2 & 76 & 43 & $\mathrm{CCK}$ & Average \\
\hline 29 & 75 & 43 & $\mathrm{KCT}$ & Average \\
\hline 17 & 74 & 42 & $\mathrm{KCS}$ & Average \\
\hline 23 & 68 & 39 & $\mathrm{KCS}$ & Difficult \\
\hline 4 & 64 & 36 & SCK & Difficult \\
\hline 18 & 62 & 35 & $\mathrm{KCS}$ & Difficult \\
\hline 11 & 60 & 34 & $\mathrm{CCK}$ & Difficult \\
\hline 12 & 60 & 34 & CCK & Difficult \\
\hline 20 & 55 & 31 & $\mathrm{KCS}$ & Difficult \\
\hline 34 & 55 & 31 & $\mathrm{KCT}$ & Difficult \\
\hline 30 & 53 & 30 & $\mathrm{KCT}$ & Difficult \\
\hline 14 & 49 & 28 & SCK & Difficult \\
\hline 33 & 49 & 28 & SCK & Difficult \\
\hline 8 & 46 & 26 & $\mathrm{KSC}$ & Difficult \\
\hline 5 & 46 & 26 & SCK & Difficult \\
\hline 24 & 37 & 21 & CCK & Difficult \\
\hline 31 & 37 & 21 & SCK & Difficult \\
\hline 1 & 35 & 20 & $\mathrm{CCK}$ & Very Difficult \\
\hline 16 & 32 & 18 & $\mathrm{KCS}$ & Very Difficult \\
\hline 21 & 31 & 18 & $\mathrm{KCS}$ & Very Difficult \\
\hline 25 & 30 & 17 & $\mathrm{KCT}$ & Very Difficult \\
\hline 35 & 23 & 13 & SCK & Very Difficult \\
\hline 22 & 20 & 11 & $\mathrm{KCT}$ & Very Difficult \\
\hline 26 & 20 & 11 & $\mathrm{KCT}$ & Very Difficult \\
\hline 32 & 18 & 10 & $\mathrm{KCT}$ & Very Difficult \\
\hline 28 & 17 & 10 & $\mathrm{KCT}$ & Very Difficult \\
\hline 27 & 11 & 6 & $\mathrm{KCT}$ & Very Difficult \\
\hline \multicolumn{5}{|c|}{$N=176$} \\
\hline & Common $\mathrm{Cor}$ & t Knowledge & & \\
\hline & Specialized C & ent Knowledge & & \\
\hline & Knowledge of & ntent and Students & & \\
\hline & Knowledge of & ontent and Teaching & & \\
\hline
\end{tabular}

Table 3. Description of the items in the test found difficult by student teachers.

\begin{tabular}{|c|c|}
\hline Item 1 & Identifying a correct definition of 0 \\
\hline Item 16 & $\begin{array}{l}\text { Asking students an explanation why a procedure works in investigating patterns on whole } \\
\text { number addition }\end{array}$ \\
\hline Item 21 & Choosing a challenging problem for students in developing proportional reasoning \\
\hline Item 25 & $\begin{array}{l}\text { Choosing the best example that will help students develop different strategies for comparing } \\
\text { and ordering fractions }\end{array}$ \\
\hline Item 35 & Justifying why subtraction of whole number works \\
\hline Item 22 & Using a story problem to represent division of fractions \\
\hline Item 26 & Using a sequence of examples for solving a problem on division of whole numbers \\
\hline Item 28 & Using appropriate teaching materials for a lesson on defining triangles \\
\hline Item 32 & Choosing appropriate examples for introducing primes and composites \\
\hline Item 27 & Choosing appropriate examples for dividing fractions \\
\hline
\end{tabular}

Relationship Between Subject Matter Knowledge and Pedagogical Content Knowledge

The relationship between subject matter knowledge and pedagogical content knowledge was also investigated in 
this study. The MKT scores has mean of 6.29 with standard deviation of 2.28 , while the mean of the PCK scores is 5.26 and standard deviation of 1.80. A Pearson product-moment correlation coefficient was run to identify whether a relationship between the subject matter knowledge and pedagogical content knowledge of pre-service exists. Results in Table 5 show a moderate positive significant relationship between MKT and PCK, $(r=.307, p=.000)$. However, the correlation coefficient indicates a moderate relationship. Studies done by Asante N., \& Mereku, (2012); Pinamang, \& Cofie, (2017); Jakobsen, et al., (2018) also resulted to a weak positive relationship between pre-service teachers' content knowledge and pedagogical content knowledge, $(\mathrm{r}(82)=.044, \mathrm{p}<.05)$.

Table 5. Pearson correlation between subject matter knowledge and pedagogical content knowledge

\begin{tabular}{lllc}
\hline & & Pedagogical Content \\
Respondents & & Knowledge \\
\hline \multirow{3}{*}{ Student Teachers } & & r & $0.307^{* *}$ \\
& Subject Matter & Sig. (2-tailed) & 0.000 \\
& Knowledge & $\mathrm{N}$ & 176 \\
\hline
\end{tabular}

**. Correlation is significant at the 0.05 (2-tailed).

\section{Conclusions and Recommendations}

Findings of the study indicate that the MKT levels among of pre-service elementary teachers are low across all domains are very low. A large number of the PST's have low levels and an inadequate understanding of the mathematics content knowledge and they also do not have the pedagogical content knowledge that will help them teach content in a manner appropriate to children. Subject matter knowledge and pedagogical content knowledge are key components of teacher competence that affect student progress. These findings highlight the quality of the training these PST's are exposed to in their teacher preparation program. The result of the study has an important implication for teacher preparation program. If pre-service teachers are expected to acquire the mathematical knowledge necessary for teaching at their training institutions, then the colleges and universities should be a place where pre-service teachers can acquire this knowledge. Therefore, aside from the required content courses, a specialized mathematics methods course should be included in the teacher curriculum. These courses will serve as venues where students can demonstrate the mathematical and pedagogical knowledge acquired in the content courses.

This study has without its limitations and one is the instrument used to measure MKT. Although, the instrument was subjected to a classical test theory (CTT) method of establishing validity and reliability, it is recommended that before it can be used in another study, an item response theory (IRT) specifically a two parameter model validation process should be undertaken. IRT assumes that the ability of the examinee is independent of the test items and the ability of the group tested, hence an examinee with a high ability has a high probability of answering an item correctly (Hambleton, \& Jones, 2012). Thus, a researcher will be able to classify the performance levels of examinees for every item in a test. Indeed, teachers with adequate mathematical knowledge for teaching is recognized by experts and researchers as an important factor that influences student performance in mathematics. Hence, evaluation of this knowledge using a valid and reliable instrument could provide an initial database which can be used in developing and enhancing pre-service teachers' knowledge for teaching mathematics during their teaching preparation program.

\section{References:}

Agsalud, P. L. (2017). Teaching effectiveness of the teacher education faculty members in Pangasinan State University Asingan Campus, Philippines. Asia Pacific Journal of Multidisciplinary Research, 5(1), 16-22.

Asante, J. N., \& Mereku, D. K. (2012). The effect of Ghanaian pre-service teachers' content knowledge on their mathematical knowledge for teaching basic school mathematics. African Journal of Educational Studies in Mathematics and Sciences, 10(1), 23-37.

Ball, D. L., Lubienski, S. T., \& Mewborn, D. S. (2001). Research on teaching mathematics: The unsolved problem of teachers' mathematical knowledge. Handbook of research on teaching, 4, 433-456.

Hambleton, R. K., \& Jones, R. W. (2012). Comparison of classical test theory and item response theory and their applications to test development, Instructional Topics in Educational Measurement Series 16.

Blömeke, S., \& Kaiser, G. (2014). Theoretical framework, study design and main results of TEDS-M. In International perspectives on teacher knowledge, beliefs and opportunities to learn (pp. 19-47). Springer, Dordrecht.

Bentley, B., \& Bossé, M. J. (2018). College students' understanding of fraction operations. International Electronic Journal of Mathematics Education, 13(3), 233-247.

Ding, L., He, J., \& Leung, F. K. S. (2014). Relations between subject matter knowledge and pedagogical content knowledge: A study of Chinese pre-service teachers on the topic of three-term ratio. The Mathematics Educator, 15(2), 50-76.

Hill, H. C., Schilling, S. G., \& Ball, D. L. (2004). Developing measures of teachers' mathematics knowledge for 
teaching. The elementary school journal, 105(1), 11-30.

Hill, H. C., Sleep, L., Lewis, J. M., \& Ball, D. L. (2007). Assessing teachers' mathematical knowledge for teaching. Second handbook of research on mathematics teaching and learning: A project of the National Council of Teachers of Mathematics, 112.

Jakobsen, A., \& Kazima, M. (2014). Mathematical knowledge for teaching among prospective teachers in Malawi. Nordic Research in Mathematics Education: Proceedings of NORMA14, 101-110.

Kasoka, D. N., Kazima, M, \& Jakobsen, A. (2016). Adaptation of mathematical knowledge for teaching number concepts and operations measures for use in Malawi. In W. Mwakapenda, T. Sedumedi, \& M. Makgato (Eds.), Proceedings of the 24th Annual Conference of the Southern African Association for Research in Mathematics, Science and Technology (pp. 100-110). Pretoria, South Africa: SAARMSTE.

Krauss, S., Brunner, M., Kunter, M., Baumert, J., Blum, W., Neubrand, M., \& Jordan, A. (2008). ] Pedagogical content knowledge and content knowledge of secondary mathematics teachers. Journal of Educational Psychology, 100(3), 716.

Leung, I. K., \& Carbone, R. E. (2013). Pre-service teachers' knowledge about fraction division reflected through problem posing. The Mathematics Educator, 14(1\&2), 80-92.

Loewenberg Ball, D., Thames, M. H., \& Phelps, G. (2008). Content knowledge for teaching: What makes it special? Journal of teacher education, 59(5), 389-407.

Lord, F. M. (1952). The relation of the reliability of multiple-choice tests to the distribution of item difficulties. Psychometrika, 17(2), 181-194.

Ma, L. (1999). Knowing and teaching elementary mathematics: Teachers' understanding of fundamental mathematics in China and the United States. Mahwah, NJ: Lawrence Erlbaum Associates.

Maligalig, D. S., \& Albert, J. R. G. (2008). Measures for assessing basic education in the Philippines (No. 200816). PIDS Discussion Paper Series.

Mapolelo, D. C., \& Akinsola, M. K. (2015). Preparation of mathematics teachers: Lessons from review of literature on teachers' knowledge, beliefs, and teacher education. International Journal o Educational Studies, 2(1), 01-12.

Mewborn, D. (2001). Teachers content knowledge, teacher education, and their effects on the preparation of elementary teachers in the United States. Mathematics Teacher Education and Development, 3(1), 28-36.

Nillas, L. (2003). Division of fractions: Preservice teachers' understanding and use of problem solving strategies. The Mathematics Educator, 7(2), 96-113.

Nolan, B., Dempsey, M., Lovatt, J., \& O'Shea, A. (2015). Developing mathematical knowledge for teaching (MKT) for pre-service teachers: a study of students' developing thinking in relation to the teaching of mathematics. Proceedings of the British Society for Research into Learning Mathematics, 35(1).

Ogena, E. B., Lana, R. D., \& Sasota, R. S. (2010). Performance of Philippine high schools with special curriculum in the 2008 trends in international mathematics and science study (TIMSS-Advanced).

Pinamang, I., \& Cofie, P. O. (2017). Pre-service teachers' content knowledge and pedagogical content knowledge in teaching geometric transformation. African Journal of Educational Studies in Mathematics and Sciences, 13(1), 63-70.

Shahbari, J. A. (2017). Mathematical and pedagogical knowledge amongst first-and second-grade in-service and pre-service mathematics teachers. International Journal for Mathematics Teaching \& Learning, 18(1).

Shulman, L. S. (1986). Those who understand: Knowledge growth in teaching. Educational Researcher, 15(2), 414.

Sogillo, R. R. O., Guimba, W. D., \& Alico, J. C. Assessment of Mathematics Teachers in a Public and a Private School: Implications to the Quality of Teaching Secondary Mathematics.

Son, J. W., \& Lee, J. E. (2016). Pre-service teachers' understanding of fraction multiplication, representational knowledge, and computational Skills. Mathematics Teacher Education and Development, 18(2), 5-28.

Tavakol, M., \& Dennick, R. (2011). Making sense of Cronbach's alpha. International journal of medical education, 2, 53

Tatto, M. T., \& Senk, S. (2011). The mathematics education of future primary and secondary teachers: Methods and findings from the Teacher Education and Development Study in Mathematics. Journal of Teacher Education, 62(2), 121-137.

Turnuklu, E. B., \& Yesildere, S. (2007). The pedagogical content knowledge in mathematics: Pre-service primary mathematics teachers' perspectives in Turkey. Issues in the Undergraduate Mathematics Preparation of School Teachers, 1 . 